\title{
Evaluation of Biochemical Bone Markers in Children with Nephrotic Syndrome with Correlation to Its Severity \\ Sahbaa Fehr Mohamed Hafez ${ }^{1}$, Dina Mohamed Shokry ${ }^{1}$, Mansour Khamees Faraj ${ }^{* 1}$, Samar Mahmoud Abd Elhalim ${ }^{2}$
}

Departments of ${ }^{1}$ Pediatrics and ${ }^{2}$ Medical Biochemistry, Faculty of Medicine - Zagazig University, Egypt. *Corresponding author: Mansour Khamees Faraj, Mobile: (+20)01097046456, E-mail: manskhamis.21.10.1987@gmail.com

\begin{abstract}
Background: Vitamin D is a vital component of bone metabolism and calcium homeostasis, and its deficiency is known to cause rickets, osteomalacia and hypocalcemia.

Objective: The aim of this study was to evaluate vitamin D level in patients with nephrotic syndrome and its relation to calcium.

Patients and methods: This study was a case-control study carried out at Pediatric Nephrology Unit Pediatric Department, Faculty of Medicine, Zagazig University Hospitals from June 2020 to December 2020. It included 108 patients divided into 2 groups; each group included 54 patients.1st group was patients with nephrotic syndrome and 2 nd group was healthy children as control group. A detailed history and clinical examination including anthropometry was taken for cases of Nephrotic syndrome admitted to the hospital. The patients underwent the following investigations: serum albumin, serum cholesterol, C3, C4, alkaline phosphatase, total calcium, ionized calcium, 25(OH) vitamin D, $\mathrm{CBC}$, renal function test, urine analysis urine albumin/creatinine ratio, 24hr urine protein and X-ray bone.

Results: There was statistically significant relation between vitamin D level and steroid response where steroid-resistant patient had lower vitamin level followed by steroid-dependent then steroid-sensitive patients. There was non-significant correlation between vitamin D and occurrence of relapse.
\end{abstract}

Conclusion: Vitamin D and calcium supplementation should be considered in nephrotic patients.

Keywords: Nephrotic syndrome (NS), Vitamin D, Biochemical bone markers.

\section{INTRODUCTION}

The most frequent glomerular disease in children is idiopathic nephrotic syndrome, which involves histological abnormalities of the kidney including minimal changes, focal segmental glomerulosclerosis and diffuse mesangial proliferation (1). Nephrotic Syndrome (NS) often has a relapsing course and usually responds to steroids ${ }^{(2)}$. Nephrotic syndrome (NS) is a clinical entity characterized by massive loss of urinary protein (primarily albuminuria) leading to hypoproteinemia resulting in edema. Nephrotic syndrome patients frequently have abnormalities in calcium metabolism that manifest as hypocalcemia. Hypocalcemia is initially attributed to hypoalbuminemia but it may also relate to a low level of ionized calcium ${ }^{(3)}$.

If the serum ionized calcium level declines below normal, clinical symptoms like neuromuscular irritability including tetany as manifested by chovstek's sign or Trousseau's sign. Patients with nephrotic syndrome (NS) lose 25-hydroxyvitamin D3 (25OHD3) in the urine and have low blood levels of this metabolite (4). Abnormal vitamin D metabolism in idiopathic NS is multifactorial, with contributions from losses of both vitamin $\mathrm{D}$ binding protein and $25(\mathrm{OH}) \mathrm{D}$ in the urine. The urinary losses of vitamin $\mathrm{D}$ binding protein may be secondary to proteinuria, overwhelming the proximal tubule reabsorption via megalin and cubilin pathways. Deficiency in $25(\mathrm{OH}) \mathrm{D}$ may lead to hypocalcemia, hyperparathyroidism, and diminished bone mineral density/content. Vitamin D deficiency has also been associated with multiple systemic effects including elevated blood pressure, metabolic syndrome,

cardiovascular disease, anemia, and impaired immune system regulation ${ }^{(5)}$.

The loss of both $25(\mathrm{OH}) \mathrm{D}$ and its binding protein (DBP) in urine is responsible for the low levels of 25hydroxycholecalciferol $[25(\mathrm{OH}) \mathrm{D}]$ documented in NS patients during a relapse. However, these low levels do not reflect steady state of body stores since most relapses are short-lasting ${ }^{(6)}$.

The evidence on vitamin $\mathrm{D}$ levels during remission of NS remains mixed but since vitamin D deficiency may contribute to osteoporosis in NS, early detection and treatment is in order ${ }^{(\mathbf{1})}$. This study aimed to evaluate vitamin D level in patients with nephrotic syndrome and its relation to calcium.

\section{PATIENTS AND METHODS}

The study was conducted in Pediatric Nephrology Unit, Pediatric Department, Faculty of Medicine, Zagazig University Hospitals from June 2020 to December 2020. This study enrolled 54 patients with nephrotic syndrome and 54 healthy control subjects.

\section{Ethical approval:}

Written informed consent was obtained from all participants' parents and the study was approved by the Research Ethical Committee of Faculty of Medicine, Zagazig University.

The work has been carried out in accordance with the Code of Ethics of the World Medical 


\section{Association (Declaration of Helsinki) for studies involving humans.}

\section{Inclusion criteria:}

Age: 2-18 years, both males and females were included. Individuals with nephrotic syndrome (steroid-sensitive nephrotic syndrome (SSNS), steroid-dependent nephrotic syndrome (SDNS) and steroid-resistant nephrotic syndrome (SRNS)).

\section{Exclusion criteria:}

Patients less than 2 years or more than 18 years. Patients with renal insufficiency [another cause nephrotic syndrome (defined by glomerular filtration rate (GFR) $<90 \mathrm{ml} / \mathrm{min} / 1.73 \mathrm{~m}^{2}$ of body surface area (BSA) as estimated by Schwartz formula)] and chronic disease e.g. chest and hepatic disease. Inherited bone diseases e.g. chondroplasia and dyschondroplasia. Obesity, malabsorption, chronic bacterial infection and autoimmune disease. Drugs that interfere with vitamin $\mathrm{D}$ as anticonvulsant drugs, antituberculous drugs and thiazide. Other medical conditions unrelated to NS that could affect bone health, growth and vitamin D status e.g. rickets, chondroplasia. Patients refused to be enrolled in the study.

All participants were subjected to full history taking, including history of nephrotic (age of onset, duration), last relapse, total number of relapses, renal biopsy results (where indicated), prior steroid sparing therapy and total glucocorticoid (prednisolone) exposure from the first dose to the last dose. Details of dietary supplementation and history of any chronic illness and fracture. Complete physical and clinical examination including, vital signs with special concentration on nephrotic syndrome signs and anthropometric measurements (weight and height). Investigations including serum albumin, serum cholesterol, C3, C4, alkaline phosphatase, total calcium, ionized calcium and $25(\mathrm{OH}) \mathrm{D}, \mathrm{CBC}$ and renal function tests. Urine analysis including urine albumin/creatinine ratio and $24 \mathrm{hr}$ urine protein. Plan X-ray bone.

\section{Statistical Analysis}

Data analysis was performed using the software SPSS (Statistical Package for the Social Sciences) version 20. Quantitative variables were described using their means and standard deviations. Categorical variables were described using their absolute frequencies and were compared using chi square test. Kolmogorov-Smirnov (distribution-type) and Levene (homogeneity of variances) tests were used to verify assumptions for use in parametric tests. Mann Whitney test and independent sample $t$ test were used to compare continuous non-parametric and parametric variables among two groups. To compare quantitative data between more than two groups, one way ANOVA test (for normally distributed data) and Kruskal Walllis test (for non-parametric data) were used. LSD and pairwise comparison were used to analyse difference between each to individual groups in patients showed significant difference on using one way ANOVA and Kruskal Wallis test respectively. Kandell tabu correlation was used to assess correlation between continuous and ordinal data. Pearson and Spearman rank correlation coefficient were used to assess strength and direction of a linear relationship between two continuous variables. Linear stepwise regression analysis was used to determine the extent to which there is a linear relationship between a dependent variable and one or more independent variables. The level of statistical significance was set at $\mathrm{P} \leq 0.05$. Highly significant difference was present if $\mathrm{p} \leq 0.001$.

\section{RESULTS}

Table (1) showed that there was statistically nonsignificant difference between the case and control groups regarding age and gender.

Table (1) Comparison between case and control groups regarding demographic data

\begin{tabular}{|c|c|c|c|c|}
\hline \multirow{2}{*}{} & \multicolumn{2}{|c|}{ Groups } & \multicolumn{2}{c|}{ Test } \\
\cline { 2 - 4 } & Case group & Control group & \multirow{2}{*}{$\mathbf{Z} / \boldsymbol{\chi}^{\mathbf{2}}$} & $\mathbf{p}$ \\
\cline { 2 - 5 } & $\mathbf{N = 5 4 ( \% )}$ & $\mathbf{N = 5 4}(\mathbf{\%})$ & & \\
\hline $\begin{array}{c}\text { Age (month): } \\
\text { Median } \\
\text { Range }\end{array}$ & 60 & 72 & -1.942 & 0.054 \\
\hline $\begin{array}{c}\text { Gender: } \\
\text { Female }\end{array}$ & $24-168$ & $28-144$ & & \multirow{2}{*}{0.054} \\
Male & $24(44.4)$ & $34(60)$ & 3.724 & \\
\hline
\end{tabular}

Z Mann Whitney test $\chi^{2}$ Chi square test

Table (2) showed that there was statistically significant difference between the case and control groups regarding serum ionized calcium (significantly lower in case group), and phosphorus (significantly higher among case group). There was statistically non-significant difference between the case and control regarding parathyroid hormone. 
Table (2): Comparison between case and control groups regarding serum calcium, phosphorus and parathyroid levels

\begin{tabular}{|c|c|c|c|c|}
\hline & \multicolumn{2}{|c|}{ Groups } & \multicolumn{2}{|c|}{ Test } \\
\hline & Case group & Control group & \multirow{2}{*}{$\mathbf{t} / \mathbf{Z}$} & \multirow[b]{2}{*}{$\mathbf{p}$} \\
\hline & $\mathrm{N}=54(\%)$ & $\mathrm{N}=54(\%)$ & & \\
\hline $\begin{array}{c}\text { Ionized Calcium }(\mathrm{mmol} / \mathrm{L}) \\
\text { Mean } \pm \mathrm{SD}\end{array}$ & $4.19 \pm 0.347$ & $4.697 \pm 0.306$ & -8.016 & $<0.001 * *$ \\
\hline $\begin{array}{c}\text { Serum phosphorus } \\
(\mathrm{mg} / \mathrm{dL}) \\
\text { Mean } \pm \mathrm{SD} \\
\end{array}$ & $4.496 \pm 0.663$ & $4.23 \pm 0.66$ & 2.039 & $0.039 *$ \\
\hline $\begin{array}{c}\text { Serum parathyroid } \\
\text { (pg/mL) } \\
\text { Median }\end{array}$ & 22.3 & 31 & -1.295 & 0.195 \\
\hline
\end{tabular}

Z Mann Whitney testt Independent sample $t$ test $* \mathrm{p}<005$ is statistically significant highly significant

Table (3) showed that there was statistically significant difference between case and control groups regarding serum vitamin D (significantly lower among case group).

Table (3): Comparison between the case and control regarding vitamin D

\begin{tabular}{|c|c|c|c|c|}
\hline \multirow{3}{*}{ Vitamin D } & \multicolumn{2}{|c|}{ Groups } & \multicolumn{2}{|c|}{ Test } \\
\hline & Case group & Control group & & \\
\hline & $\mathrm{N}=54(\%)$ & $\mathrm{N}=54(\%)$ & $\mathbf{Z}$ & $\mathbf{p}$ \\
\hline $\begin{array}{c}\text { Vitamin D }(\mathbf{n g} / \mathbf{m l}) \\
\text { Median }\end{array}$ & 13.6 & 37.1 & -7.989 & $<0.001 * *$ \\
\hline
\end{tabular}

Z Mann Whitney test ${ }^{* *} \mathrm{p} \leq 0.001$ is statistically highly significant

Table (4) showed that there was statistically non-significant correlation between vitamin D and either serum albumin, total protein, cholesterol, alkaline phosphatase, albumin/creatinine ratio, C3 or C4. There was statistically positive significant correlation between vitamin D and ionized calcium. There was statistically significant negative correlation between vitamin $\mathrm{D}$ and serum phosphorus.

Table (4): Correlation between Vitamin D level and laboratory data among nephrotic group

\begin{tabular}{|l|c|c|}
\hline \multicolumn{1}{|c|}{ Parameter } & \multicolumn{2}{c|}{ Vitamin D } \\
\cline { 2 - 3 } & $\mathbf{r}$ & $\mathbf{p}$ \\
\hline Serum albumin (g/dL) & 0.038 & 0.783 \\
\hline Serum total protein (g/dL) & 0.147 & 0.288 \\
\hline Serum cholesterol (mg/dL) & -0.091 & 0.512 \\
\hline Alkaline phosphatase (IU/L) & -0.124 & 0.370 \\
\hline Albumin/creatinine ratio & 0.175 & 0.206 \\
\hline Ionized calcium (mmol/L) & 0.32 & $0.045^{*}$ \\
\hline Phosphorus (mg/dL) & -0.381 & $0.004^{*}$ \\
\hline PTH (pg/mL) & -0.045 & 0.744 \\
\hline C3 (mg/dL) & 0.139 & 0.317 \\
\hline C4 (mg/dL) & -0.036 & 0.794 \\
\hline
\end{tabular}

r Spearman rank correlation coefficient $* p<0.05$ is statistically significant

Table (5) showed that there was statistically significant correlation between vitamin D level and steroid response. On pairwise comparison, the difference was significant between steroid-resistant and dependent. There is non-significant correlation between vitamin D and occurrence of relapse. 
Table (5): Relation between vitamin D level and disease specific data

\begin{tabular}{||c|c|c|c|c||}
\hline \multirow{2}{*}{ Parameter } & Vitamin D & \multicolumn{2}{|c|}{ Test } & \multirow{2}{*}{$\begin{array}{c}\text { Pairwise } \\
\text { comparison }\end{array}$} \\
\cline { 2 - 5 } & Median (range) & KW/Z & P & \\
Steroid response & & & & P1 $0.028^{*}$ \\
SRNS & 11 & 6.876 & $0.032 *$ & P2 0.19 \\
SSNS & 25 & & & P3 0.503 \\
SDNS & 12.3 & & & \\
\hline Relapse: & 29.3 & 3.692 & 0.158 & \\
First attack & 14.4 & & & \\
Infrequent & 11 & & & \\
Frequent & &
\end{tabular}

KW Kruskal Wallis test Z Mann Whitney test *p<0.05 is statistically significant $\mathbf{p} 1$ the difference between steroidresistant and steroid-dependent $\mathbf{p 2}$ the difference between steroid-sensitive and steroid-resistant $\mathbf{p 3}$ the difference between steroid-dependent and steroid-sensitive

Table (6) showed that there was statistically significant negative correlation between serum ionized calcium and total protein, and serum PTH. There is statistically significant positive correlation between serum ionized calcium and serum albumin. There was statistically non-significant correlation between serum ionized calcium and either serum cholesterol, alkaline phosphatase, albumin/creatinine ratio, serum phosphorus, $\mathrm{C} 4$ or $\mathrm{C} 3$.

Table (6): Correlation between serum ionized calcium and laboratory measurements

\begin{tabular}{|l|c|c|}
\hline \multirow{2}{*}{\multicolumn{1}{|c|}{ Parameter }} & \multicolumn{2}{c|}{ Serum ionized calcium } \\
\cline { 2 - 3 } & $\mathbf{r}$ & $\mathbf{p}$ \\
\hline Serum albumin & $0.310^{\infty}$ & $0.022^{*}$ \\
\hline Serum total protein & $-0.296^{\infty}$ & $0.016^{*}$ \\
\hline Serum cholesterol & $0.165^{\infty}$ & 0.234 \\
\hline Alkaline phosphatase & -0.032 & 0.818 \\
\hline Albumin/creatinine ratio & 0.126 & 0.363 \\
\hline Phosphorus & $-0.190^{\infty}$ & 0.169 \\
\hline PTH & -0.313 & $0.021^{*}$ \\
\hline C3 & -0.064 & 0.645 \\
\hline C4 & -0.189 & 0.17 \\
\hline
\end{tabular}

r Spearman rank correlation coefficient ${ }^{\infty}$ Pearson correlation coefficient $* \mathrm{p}<0.05$ is statistically significant $* * p \leq 0.001$ is statistically highly significant

Table (7) showed that there was statistically non-significant relation between serum ionized calcium level and both steroid response and relapse.

Table (7): Relation between serum ionized calcium and disease specific data

\begin{tabular}{||c|c|c|c||}
\hline \multicolumn{1}{|c|}{ Parameter } & Serum ionized calcium & \multicolumn{2}{c|}{ Test } \\
\cline { 2 - 4 } & Mean \pm SD & F/t & $\mathrm{p}$ \\
\hline Steroid response & & & \\
SDNS & $4.19 \pm 0.33$ & 2.568 & 0.087 \\
SRNS & $3.97 \pm 0.11$ & & \\
SSNS & $4.25 \pm 0.39$ & & \\
\hline Relapse: & $4.32 \pm 0.42$ & 2.065 & \multirow{2}{*}{0.137} \\
First attack & $4.24 \pm 0.33$ & & \\
Infrequent & $4.09 \pm 0.32$ & & \\
Frequent & &
\end{tabular}

F One way ANOVA test $t$ Independent sample $t$ test $* \mathrm{p}<0.05$ is statistically significant 


\section{DISCUSSION}

Age of the patients ranged from 24 to 168 months with median of 60 months that does not differ significantly from control group. About $55.6 \%$ versus $40 \%$ in case and control groups were males. Due to good randomization, there were statistically non-significant differences between both groups regarding demographic data that helped to undermine any confounders. Banerjee et $\boldsymbol{a l} .{ }^{(7)}$ studied 40 patients with NS, their ages ranged from 4 years to 10 years with median 6.25 years. Kiran and Kumar, ${ }^{(8)}$ also agree with us in age range.

There was statistically significant difference between the case and control groups regarding serum ionized calcium (significantly lower in case group; 4.19 $\mathrm{mg}$ versus $4.697 \mathrm{mg} / \mathrm{dl}$ ), and phosphorus (significantly higher among case group; $4.496 \mathrm{mg} / \mathrm{dL}$ versus 4.23 $\mathrm{mg} / \mathrm{dL}$ within control group). Results of the study by El Kersh et al.${ }^{(9)}$ agree with the current one in that children with active SSNS had number of disturbances in calcium homeostasis including high phosphorus and low total and ionized calcium. Weng et al. ${ }^{\left({ }^{10)}\right.}$ reported that hypocalcemia in patients with NS reported in this study are in line with Kosan $\boldsymbol{e t}$ al. ${ }^{(\mathbf{1 1 1})}$.

Glucocorticosteroids cause hypocalcemia by reducing intestinal calcium absorption and increased urinary calcium losses Ribeiro et al. ${ }^{\mathbf{( 1 2 )}}$. However, some studies have reported normal serum calcium levels in children with NS due to increased PTH ${ }^{(13)}$.

The present study showed that patients had significantly higher levels of mean serum phosphorus than the control group, which is in harmony with studies by ElKersh et al. ${ }^{(9)}$, Feinstein et al. ${ }^{(14)}$, Sexton et al. ${ }^{(15)}$ and El-Mashad et al. ${ }^{(16)}$. Hyperphosphatemia in NS may be due to intravascular volume depletion and massive proteinuria, which could increase tubular sodium and phosphate reabsorption (17) or due to increased urinary excretion of insulin-like growth factor 1 that is known to stimulate phosphate tubular reabsorption ${ }^{(\mathbf{1 4})}$. In contrast, other studies conducted on NS patients reported normal serum phosphorus levels (18).

There was statistically non-significant difference between the case and control groups regarding parathyroid (median PTH were 22.3 and 31 within both groups respectively; yet the range was higher among case group from 4 to 72). This contradicts the results of El Kersh et $\boldsymbol{a l} .{ }^{(9)}$ where mean serum PTH level was significantly higher in the patients' group when compared to the control group. Elsaeed et al. (19) reported that serum PTH was significantly higher among NS group.

There was statistically significant difference between the case and control groups regarding serum vitamin D (Median level $13.6 \mathrm{ng} / \mathrm{mL}$ within case group versus $37.1 \mathrm{ng} / \mathrm{mL}$ within control group). This comes in harmony with a previous study by ElKersh $\boldsymbol{e t}$ al. ${ }^{(9)}$, Marzouk et al. ${ }^{(20)}$, Nielsen et al. ${ }^{(21)}$ and Elsaeed et al.
(19). Moreover, Selewski et al. $^{(5)}$ reported that all children with NS at diagnosis had 25(OH)D deficiency and the majority continued to have a deficiency at 2-4 months and that supplemental vitamin $\mathrm{D}$ decreased the odds of $25(\mathrm{OH}) \mathrm{D}$ deficiency at follow-up supporting a role for supplementation in incident NS. The loss of both $25(\mathrm{OH}) \mathrm{D}$ and its binding protein in urine could be the cause of vitamin D deficiency ${ }^{(22)}$. Patients with nephrotic syndrome (NS) lose 25-hydroxyvitamin D in urine and can have low 25-hydroxyvitamin D (25$\mathrm{OH}) \mathrm{D}$ circulates in blood, bound to Vitamin D binding protein. Thus, patient with nephrotic syndrome loses 25-hydroxyvitamin $\mathrm{D}$ with protein in urine. If the magnitude of such losses of 25-hydroxyvitamin D is marked and its duration is prolonged, a state of vitamin$D$ deficiency may ensues and be responsible for the abnormalities of calcium homeostasis ${ }^{(23)}$. Although it is reasonable to assume that both the severity and the duration of proteinuria are critical factors in determining the magnitude and the chronicity of vitamin D deficiency in NS patients because of the loss of DBP in urine Levin et $^{\text {al }}{ }^{(24)}$, there is non-significant positive correlation between vitamin D level and, serum albumin and total protein.

There was significant positive correlation between serum calcium and vitamin D levels, and negative correlation between serum phosphate and vitamin D levels. However, there was no significant correlation between alkaline phosphatase and vitamin D levels. This is contradictory with Mittal $\boldsymbol{e t} \boldsymbol{a l} .{ }^{(25)}$ where there was no correlation between serum calcium and $25 \mathrm{OH}$ vitamin D levels.

There was non-significant negative correlation between vitamin $\mathrm{D}$ and alkaline phosphatase (ALP). According to Banerjee et al. ${ }^{(7)}$, ALP levels cannot be used for vitamin D deficiency screening in NS as they found that ALP level was lower after relapse in NS when compared to the controls, which may be due to an inhibitory action of steroids on osteoblasts.

Vitamin D deficiency causes a decrease in the intestinal calcium absorption resulting in hypocalcemia, which leads to PTH secretion, increased conversion of $25(\mathrm{OH}) \mathrm{D}$ to $1,25-(\mathrm{OH}) 2 \mathrm{D}$, increased calcium reabsorption and phosphate loss from renal tubules, and reduction in bone mineralization ${ }^{(26)}$.

There was significant relation between vitamin $\mathrm{D}$ level and steroid response. On pairwise comparison, the difference is significant between steroid-resistant and dependent, where steroid-resistant patients had lower vitamin $\mathrm{D}$ level followed by steroid-dependent then steroid-sensitive patients. This agrees with Marzouk $\boldsymbol{e t}$ al. ${ }^{(20)}$ who reported that vitamin D was significantly lower in those with steroid-resistant NS. A crosssectional study done by Weng et al. ${ }^{(\mathbf{1 0})}$ who measured $25(\mathrm{OH}) \mathrm{D}$ in children with SRNS, SSNS and healthy controls and showed marked vitamin D deficiency in SRNS than SSNS and controls. 
There was non-significant association between vitamin D and frequency of relapse, however patients on first attack had highest vitamin D level followed by infrequent and frequent relapses. This can point to that relapse had a role in vitamin D deficiency.

This partly agrees with Marzouk $\boldsymbol{e t}$ al. ${ }^{(20)}$ and Banerjee et al. ${ }^{(7)}$, where there was significant negative correlation between vitamin $\mathrm{D}$ and number of relapses. This partly agrees with a study conducted by Weng $\boldsymbol{e t}$ al. (10) who reported that number of relapses did not affect the concentration of $25 \mathrm{OH}$ vitamin $\mathrm{D}$. Whereas, in a study conducted by Biyikli et al. ${ }^{(27)}$, there was a significant difference in $25 \mathrm{OH}$ vitamin D levels between frequent relapsers and infrequent relapse, which is similar to our present study. In disagreement with ours, NHANES III (National Health and Nutrition Examination Survey) reported that low 25(OH)D levels were significantly associated with an increased prevalence of albuminuria (number of relapses) among the general adult population ${ }^{(28)}$. Low vitamin D levels can cause proteinuria as vitamin $\mathrm{D}$ suppresses transcription of renin that activates the reninangiotensin system, which contributes to the reduction of proteinuria through hemodynamic mechanisms ${ }^{(29)}$.

In the current study, there was non-significant correlation between serum ionized calcium and albumin/creatinine ratio. Review of the results of some studies dealt with calcium homeostasis reported low ionized calcium and concluded that the ionized calcium level is related to the severity and duration of proteinuria (30).

The present study showed significant positive correlations between serum ionized calcium and serum albumin and significant negative correlations between serum ionized calcium and total protein. Hossain $\boldsymbol{e t}$ al. (30) agree with the current study as they reported that there was a positive correlation between serum albumin level and ionized calcium in idiopathic nephrotic syndrome and dis-harmony with El kersh et al. ${ }^{\left({ }^{(9)}\right.}$.

In the current study, there was statistically nonsignificant relation between serum ionized calcium level and both steroid response and relapse. Patients with steroid sensitivity had highest level followed by steroid-dependent, then steroid-resistant with the least value.

In a study conducted by Mehta and Nanda ${ }^{(31)}$, serum calcium levels were significantly lower in frequent relapsers and steroid-dependent nephrotic syndrome compared to first episode of nephrotic syndrome and infrequent relapses. Hypocalcemia has been traditionally related to proteinuria and hypoalbuminemia in active phase of NS ${ }^{(32)}$. Although, this can explain the decrease in total calcium, it cannot directly explain the low ionized calcium during the active stage of the disease. Moreover, serum ionized calcium levels did not reach normal levels even after remission and resolution of proteinuria ${ }^{\left({ }^{(9)}\right.}$. This might be attributed to other changes initiated by proteinuria, such as persistent low levels of $25(\mathrm{OH}) \mathrm{D}$ and that $25(\mathrm{OH}) \mathrm{D}$ might take a longer duration to return back to normal levels, despite the resolution of proteinuria.

\section{Conclusion:}

Vitamin D and calcium supplementation should be considered in nephrotic patients. Renal biopsy should be considered as FSGS becomes a frequent histopathologic change. Large scale multicenter study should be applied to study behavior of these biomarkers over different stages of disease, which can also involve vitamin D and calcium supplementation to examine their role in maintaining bone health.

\section{REFERENCES}

1. Sinha N, Wade P, Ghildiyal R et al. (2018): Biochemical bone markers in children with steroid sensitive nephrotic syndrome in remission. Int J Contemp Pediatr., 5 (4): 158863.

2. Alshami A, Roshan A, Catapang M et al. (2017): Indications for kidney biopsy in idiopathic childhood nephrotic syndrome. Pediatric Nephrology, 32 (10): 1897-1905.

3. Chaudhury G, Hanif M, Afroz M et al. (2016): Correlation between Serum Magnesium and Calcium Level in Children with Idiopathic Nephrotic Syndrome during Nephrosis. Bangladesh Journal of Child Health, 40 (3): 139-143.

4. Garniasih D (2011): The relationship between serum albumin and calcium in Children with Nephrotic Syndrome. Sari Pediatrics, 10: 100-106.

5. Selewski D, Chen A, Shatat I et al. (2016): Vitamin D in incident nephrotic syndrome: a Midwest Pediatric Nephrology Consortium study. Pediatric Nephrology, 31 (3): 465-472.

6. Greenbaum L, Benndorf R, Smoyer W (2012): Childhood nephrotic syndrome--current and future therapies. Nat Rev Nephrol., 8 (8): 445- 58.

7. Banerjee S, Basu S, Sengupta J (2013): Vitamin D in nephrotic syndrome remission: A case-control study. Pediatr Nephrol., 28: 1983-9.

8. Kiran P, Kumar B (2017): Clinico-biochemical evaluation of nephrotic syndrome in children. International Journal of Contemporary Medical Research, 4 (10): 2214-2217.

9. El Kersh M, Sharaki O, Omar O et al. (2018): Ionized calcium, 25-hydroxyvitamin D, and parathyroid hormone in children with steroid-sensitive nephrotic syndrome. Alexandria Journal of Pediatrics, 31 (3): 13236.

10. Weng F, Shults J, Herskovitz $\mathrm{R}$ et al. (2012): Vitamin $\mathrm{D}$ insufficiency in steroid-sensitive nephrotic syndrome in remission. Pediatr Nephrol., 20: 56- 63.

11. Koşan C, Ayar G, Orbak Z (2012): Effects of steroid treatment on bone mineral metabolism in children with Glucocorticoid-sensitive Nephrotic Syndrome. West Indian Medical Journal, 61 (6): 627-30.

12. Ribeiro D, Zawadynski S, Pittet L et al. (2015): Effect of glucocorticoids on growth and bone mineral density in children with nephrotic syndrome. Eur J Pediatr., 174: 911-7.

13. Panczyk-Tomaszewska M, Adamczuk D, Kisiel A et al. (2015): Markers of bone metabolism in children with nephrotic syndrome treated with corticosteroids. 
Advances in Experimental Medicine and Biology, 840: 21-8.

14. Feinstein S, Becker-Cohen R, Rinat $C$ et al. (2006): Hyperphosphatemia is prevalent among children with nephrotic syndrome and normal renal function. Pediatric Nephrology, 21 (10): 1406-1412.

15. Sexton D, Kinsella S, Eustace J (2013): Serum phosphate varies with degree of proteinuria in nephrotic syndrome and is associated with elevated pulse wave velocity. J Nephrol., 26: 540-548.

16. El-Mashad G, El-Hawy M, El-Hefnawy S et al. (2017) Bone mineral density in children with idiopathic nephrotic syndrome. J Pediatr., 93: 142-147.

17. Walker J, Yan T, Quamme G (1987): Presence of multiple sodium-dependent phosphate transport processes in proximal brush-border membrane. Am J Physiol., 252 (Pt 2): 226-231.

18. Lisa C, Julia M, Kusuma $P$ et al. (2011): Risk factors for low bone density in pediatric nephrotic syndrome. Paediatrica Indonesiana, 51: 61-65.

19. Elsaeed G, Fadel F, El-Sonbaty $M$ et al. (.2020): Zinc, Copper and Selenium in Children with Idiopathic Nephrotic Syndrome: Relationship to Parathyroid Hormone \& Proteinuria. Current Science International, 9: 431-437.

20. Marzouk, H, Ghobrial, E, Khorshied M et al. (2019): Vitamin D level in nephrotic syndrome, Factors of impact? Geget., 14 (2): 53-61.

21. Nielsen C, Jensen J, Cortes D (2015): Vitamin D status is insufficient in the majority of children at diagnosis of nephrotic syndrome. Dan Med J., 62 (2): 1-5.

22. Grymonprez A, Proesmans W, Van Dyck M (1995): Vitamin D metabolites in childhood nephrotic syndrome. Pediatr Nephrol., 9: 278-281.
23. Kinra S, Rath B, Kabi B (2000): Indirect quantification of lipid peroxidation in steroid responsive nephrotic syndrome. Arch Dis Child, 82: 76-81.

24. Levin A, Bakris G, Molitch M (2007): Prevalence of abnormal serum vitamin D, PTH, calcium, and phosphorus in patients with chronic kidney disease: results of the study to evaluate early kidney disease. Kidney Int., 71: 31-38.

25. Mittal S, Dash S, Tiwari S et al. (1999): Bone histology in patients with nephrotic syndrome and normal renal function. Kidney Int., 55 (5): 1912-9.

26. Lips P (2006): Vitamin D physiology. Prog Biophys Mol Biol., 92: 4-8.

27. Biyikli N, Emre S, Sirin A et al. (2004): Biochemical bone markers in nephrotic children. Pediatr Nephrol., 19 (8): 869-73.

28. De Boer I, Ioannou G, Kestenbaum B (2007): 25Hydroxyvitamin D levels and albuminuria in the Third National Health and Nutrition Examination Survey (NHANES III): Am J Kidney Dis., 50: 69-77.

29. Freundlich M, Quiroz Y, Zhang Z (2008): Suppression of renin-angiotensin gene expression in the kidney by paricalcitol. Kidney Int., 74: 1394-1402.

30. Hossain A, Mostafa G, Mannan K (2016): Correlation between serum albumin level and ionized calcium in idiopathic nephrotic syndrome in children. Urol J., 3 (2): 44-47.

31. Mehta P, Nanda S (2016): Comparison of calcium metabolism in different subgroups of nephrotic syndrome in children. Indian J Child Health, 3 (3): 20162019.

32. Esmaeeili M, Azarfar A, Hoseinalizadeh S (2015): Calcium and vitamin D metabolism in pediatric nephrotic syndrome; an update on the existing literature. International Journal of Pediatrics, 3 (2): 103-109. 